\title{
Rethinking Loneliness-A Qualitative Study about Adolescents' Experiences of Being an Outsider in Peer Group
}

\author{
Riikka Korkiamäki \\ School of Management, University of Tampere, Tampere, Finland \\ Email: Riikka.korkiamaki@uta.fi \\ Received 5 June 2014; revised 9 July 2014; accepted 28 July 2014 \\ Copyright (C) 2014 by authors and Scientific Research Publishing Inc. \\ This work is licensed under the Creative Commons Attribution International License (CC BY). \\ http://creativecommons.org/licenses/by/4.0/

(c) (i) Open Access

\begin{abstract}
Friends and peers are remarkably important to young people, and problems in peer relations are often causes of adolescents' emotional stress. The purpose of this study was to investigate adolescents' views about what it means to be excluded in peer group and how this kind of experience is linked to their emotional wellbeing. The study exploited qualitative methodology and the findings were based on adolescents' personal accounts of identifying themselves as "outsiders". The data were produced in dialogical interviews with 126 Finnish adolescents. As a result, four different types of being an outsider were identified. These were found to be closely attached to emotional stress and feeling of loneliness experienced by adolescents. The results imply that adolescents' loneliness should not be looked at as a single category but it should rather be put into the context of young person's own meaning-making, preferences of belonging, and personal biography. The study compliments earlier studies with qualitative insight and experiential accounts about adolescent's self-perceived experiences of peer exclusion. These could be valuable in practices of psychology, psychiatry, social work and youth work, in seeking to understand adolescents' lived worlds and their ways of interpreting peer interaction.
\end{abstract}

\section{Keywords}

Friendship, Loneliness, Peer Relations, Social Exclusion, Youth

\section{Introduction}

Jerome S. Bruner states in his foreword to Judy Dunn's (Dunn, 2004) Children's Friendships that "being friendless is a form of lonely hell”. Many others—scientists, professionals, and people with experiential know- 
ledge alike-may easily agree. Lack of friends is recognized to cause depression, anxiety, and other emotional problems, and to correlate with low self-respect, irrational fears, deviance, personality disorders, social exclusion, and poverty (Junttila, 2010; Qualter \& Munn, 2002; Asher \& Paquette, 2003). While this resonates with people of all generations, it is suspected to be especially true with teenagers, whose identities, self-esteem and experiences of belonging are for large part constructed among friends and peer group. The experience of being unpopular or disliked in peer group, or lonely without a close friend, is said to cause deep feelings of sadness and despair, and may result in long-lasting pain and life-long trauma (Asher \& Coie, 1990; Asher \& Paquette, 2003; Dunn, 2004).

Adolescence is a life period which includes major changes in young person's physical, social, emotional, and cognitive growth and development (Dumont \& Provost, 1999; Thorsteinsson et al., 2013). This makes it a sensitive phase of life in which stress, concern and extreme emotions occur even when the overall life conditions are satisfactory (Romeo, 2010). However, occasionally these moods, thoughts and situations may exceed the individual resilience, which might cause increased risk of emotional difficulties and behavioral problems (Andersen \& Teicher, 2008; Thorsteinsson et al., 2013). Depression is said to be not an uncommon problem among adolescents (Costello et al., 2003; Shavers, 2014; Shugart \& Lopez, 2002), causing a risk for disability to function in society as well as in personal communities (Hankin, 2006; Shavers, 2014).

Adolescents confront various kinds of stressful life events and situations. Some of these concern family relations, school performance, future plans, and for example economic difficulties (Byrne et al., 2007; Thorsteinsson et al., 2013; Moon \& Rao, 2010). One of the most important causes of adolescents' anxiety and depressive feelings are, however, relationships with same-age friends and peers. Peer relations are of extreme significance to young people who often find it difficult to identify themselves with other age groups, namely children and adults. Same-age friends and peers are important sources of support, trust, and positive emotions, but they also form a major part of what strains, upsets, and stresses young people. In addition to all the fun and pleasures provided by friends, also teasing, bullying, victimization, betrayals, and rejection are the attributes that come along with adolescents' peer relations. As Dunn (2004) puts it, children and young people can "make or break each other's pleasure and happiness” (Dunn, 2004; Whitehouse et al., 2009; Rönkä et al., 2014).

One of the cruelest forms of adolescents' peer conflict is said to present itself in loneliness. Apart from its connection to low school performance (Benner, 2011), risk of physical illness (Goosby et al., 2013), and health risk behavior (Stickley et al., 2014), loneliness has been discovered to correlate with depression and emotional disorders. In a study conducted in 1989 by Goodyer and colleagues, it was found that 48 percent of adolescents who were clinically anxious or depressed had not, during the previous 12 months, experienced close, caring or supportive friendships, while the corresponding number for adolescents without emotional disorders was 16 percent (Goodyer et al., 1989; Dunn, 2004). In Brage’s study from 1993, significant relationship between adolescents' peer-group-related loneliness and depression was discovered, whereas for example family strengths and mother-youth communication did not have such an impact (Brage, 1993). Accordingly, more recent studies have discovered that adolescent loneliness, particularly if the experience is stable, is associated with diagnosed depression (Goosby et al., 2013) and the gain of depressive symptoms over time (Ladd \& Ettekal, 2013; Vanhalst et al., 2012). Moreover, based on their study with adolescents with Asperger's, Whitehouse and others (2009) reported that poor quality friendships (including conflict/betrayal) seemed to lead to loneliness and depressive symptoms. As for a comprehensive study of a Finnish birth cohort, aged 16 at the time, it was demonstrated that not having close friends, feeling unliked, being victim of bullying, and avoiding company were associated with loneliness experiences, which were also linked with feeling unhappy, sad, or depressed (Rönkä et al., 2014). There's also evidence that adolescents who experience loneliness are in risk of depression despite of parental support (Goosby et al., 2013). In Goswick’s and Jones’s (Goswick \& Jones, 1982) study almost all the loneliness components were directly linked to relationships with peers, although parental disinterest was also of some significance. These findings highlight the extreme importance of friendships, and make peer involvement key to the quality of young people's lives and their mental health (Dunn, 2004).

However, the relationship between adolescents' peer relations and their emotional wellbeing should not be looked at too straightforwardly. Firstly, there are some conflicting results regarding the links between loneliness and depressive symptoms (see Vanhalst et al., 2012), as well as mediating factors that should be examined more carefully. For example, social support is something that comes along with having close friends. Support from friends and peers is often perceived as most meaningful by adolescents compared to some other sources of support (Rueger et al., 2010; Pfeiffer et al., 2011), thus the lack of friends often means significant loss in situations 
of depressive feelings and search for support (Dunn, 2004; Thorsteinsson et al., 2013; Thorsteinsson \& Davey, 2014). Also, poor self-esteem is identified as one of the symptoms that relates to adolescent depression (Orth et al., 2008; Thorsteinsson \& Davey, 2014), while adolescents' self-esteem is par excellence created and sustained and may hence also be crushed in peer relations (Eddles-Hirsch, 2012; Valdez, 2011). On top of these and other mediators, it is worth noticing that in adolescence the relationship between loneliness and belonging is most complicated. Being alone or not having same age friends does not necessarily mean loneliness, and temporary feelings of loneliness do not inevitably cause depression. In fact, they are mundane part of most adolescents' lives (Dunn, 2004).

Hence, adolescents' loneliness is not simply related to how well they are accepted by their peers, or whether they have friends or not. Neither does a small amount of friends indicate loneliness. There are young people who seem to feel quite satisfied on their own, and others who have several friends and still feel lonely (Dunn, 2004; Korkiamäki \& Ellonen, 2010). Meanwhile, there are those who would desperately want to have friends or be part of a group but for unpredictable reasons fail to do so (Dunn, 2004). Whilst most youth find belongingness among close friends or larger peer group, peers' social and spatial orderings and labeling reputations position some adolescents outside the group. Research on popularity, acceptance and rejection has demonstrated that these excluding reputations and practices have important impact on young people's mood, adjustment, and development (Asher \& Coie, 1990; Rubin et al., 1998).

The paradox of youth networking and group sustainment is that someone's loneliness is often created by togetherness and belonging of others. Enhancing "our group" through constructing borders between "Us" and "the other" can be seen as habitual feature of adolescents' peer group formation (Eddles-Hirsch, 2012; Hopkins, 2010; Korkiamäki, 2013). This complex interrelation between belonging and being left out invites more research on adolescents' personal experiences of exclusion or being part of a group. It is important to ask how young people themselves perceive loneliness, being alone or being left out. In addition to the weighty quantitative research dominating the field, there is a need for qualitative studies on young people's experiences, meanings and definitions on how loneliness is constructed in relation to belonging, and what it means to have friends or stand as "an outsider".

Given the complex relationship between belonging and loneliness, the differing meanings of being alone, and the extreme importance of peer relations to adolescents' emotional wellbeing, the purpose of this study was to capture the variety of adolescents' views about what it means to be excluded in peer group and how this kind of "being outside" affects their emotional standpoint. Accordingly, "outsiderness" is studied as potential stress factor which might be self-perceived as loneliness and can cause depressive feelings. Simultaneously, the aim is to recognize the variance of self-reported outsider experiences, and thus avoid pathologizing adolescents' being alone. The concluding goal is thus to provide experiential information and a complementary viewpoint for youth and social workers, teachers, psychologists, and counselors to discuss about and deal with adolescents' loneliness, negative moods, and peer group belonging.

\section{Methods}

The study is part of a Finnish research project called Early Recognition in Curbing the Marginalization Risk of Children and Youth (2013-2015) that seeks to take part in current debates on early intervention by suggesting that more attention should be paid to adolescents' experiences of belonging and communality as pre-emptive measures that might narrow the risk of marginalization. The results of the project are expected to have both scientific and practical value, and relevance for policy making and end users aiming at children and young people's wellbeing and their communal and societal engagement in Finland and elsewhere. The study employs qualitative methodology.

\subsection{Data Collection and Participants}

The data collection was carried out in 2012 in two schools situated in middle-class neighbourhoods of two fairly large Finnish cities (population 250,000 - 600,000). The $5^{\text {th }}$ graders $\left(11-12\right.$ years of age) and the $9^{\text {th }}$ graders $(15$ - 16 years of age) of both schools were offered a possibility to participate in the research. The participation was voluntary, but nearly all the $5^{\text {th }}$ and $9^{\text {th }}$ graders in both schools decided to participate, resulting in $735^{\text {th }}$ grader and $539^{\text {th }}$ grader participants. 70 of them were girls and 56 were boys. Their socio-economic background was mostly middle-class, and most of them were Finnish by their ethnic and racial background, representing the 
schools' student population. Informed consent was received from these 126 adolescents as well as their parents, and the requisite permissions were granted by school officials and personnel. The matters of confidentiality, anonymity, and secrecy were respected throughout the data collection, and discussed with participants and their guardians.

The data collection was arranged in school environment during school hours, but it was conducted by researchers and carefully dissociated from academic school work. The data consist of biographical narratives which were produced through mapping exercise, dialogical interviews, and thematic essays. Firstly, the mapping exercise took place, providing first-hand information about participants' socio-spatial belonging. In the exercise, the participants marked differently scaled mapping platforms with different colours, indicating their perceptions about the marked locations (for details, see e.g. Kallio, 2014). The maps were then discussed with each participant individually in dialogical non-structured interviews with two researchers present. Each participant's individual map operated as directive for the interview, resulting in various interview themes originating on adolescent's initiatives. Regardless, all interviews included narratives about everyday life in different institutional and informal contexts, social networks and relationships, participation, and inclusion and belonging. In the course of the interviews, the reverse themes of exclusion, alienation and the problems in social relations arose, as expected. It is noteworthy that all participants chose to talk about peer relations, indicating the importance of friends and peers to young people.

The interviews took from 10 to 60 minutes, and their intensity varied greatly. After the interviews, the narratives were completed by thematic essays portraying pleasures and challenges of social relationships and sociospatial attachments. The primary focus of this study is in the accounts of belonging, exclusion, and peer relations, produced in the interviews of $9^{\text {th }}$ graders.

\subsection{Analysis}

The data were analysed as dialogical biographical narratives involving partial truths about the participants' experiential worlds, following the idea of critical documentary ethnography (see Ortner, 2002). It was central in the analysis to acknowledge the situatedness of knowledge as well as the positionality of the researchers and the participants (see Mason, 2002). The analysis of the data implemented the method of qualitative content-analysis and in-depth reading, specified in the identification of participating adolescents' peer networks, communities, and friendships, and defining the practical and qualitative features of these relationships (cf. Mayring, 2000; Titscher, 2000). In addition, the accounts of self-perceived outsiderness were identified and examined to recognize the social context of outsiderness (feeling excluded from eg. friendship/specific peer group/school mates/youth in general), the position of being an outsider (e.g. temporary/stable, strong/weak), and the emotional meaning of experiencing outsiderness, particularly whether the participants who identified themselves as outsiders expressed loneliness, depressed mood (like feeling sad, hopeless, or desperate), loss of interest or pleasure with peers, feeling low self-esteem, or ending interaction with peers (cf. Jafari et al., 2014; Shavers, 2014).

According to procedure of qualitative content-analysis, the findings were categorized in respect of both the research question and the inductive discovery (Mayring, 2000). Consequently, four categories of experiencing outsiderness were identified among participating adolescents. The descriptions of emotional stress were studied within these categories.

\section{Results}

42 of the 126 participants described their subjective experience of outsiderness, exclusion or rejection among peers. 24 (out of 73 ) of these were $5^{\text {th }}$ graders and 18 (out of 53) were $9^{\text {th }}$ graders, thus implying no significant difference in the frequency of experiencing outsiderness between the age groups. Instead, there was some variation across gender: girls described feeling left out approximately twice as often ( $155^{\text {th }}$ graders and $139^{\text {th }}$ graders) than boys (nine $5^{\text {th }}$ graders and five $9^{\text {th }}$ graders). This may be due to girls' more extrovert communication in both their dealings with each other as well as in expressing themselves in interviews, but it could also be traced back to the tacit intrigues often said to portray girls' friendships (e.g. Goodwin, 2006). However, it is important to notice that not all outsider experiences, neither boys' nor girls', were unambiguously negative. The differing "types" of being an outsider are exemplified in the following, ensued by connecting these to the emotions described by "outsiders". The exemplifying quotes are selected due to being representative of each category. 


\subsection{Types of Experiencing Outsiderness}

The participants' accounts of outsiderness included some similarities, but the differences were more striking. Four differing categories of experiencing outsiderness were identified. Within these categories, the features were rather consistent, representing the simplified types or standpoints that adolescents take in regard to their self-perceived exclusion from peers. However, it needs to be remarked that situating adolescents in these categories is by no means self-evident, as their position might change over time and from community to another. Some of them could also be situated in several categories. Thus, the typology presented here is a researcher's simplifying interpretation, and young people's individual experiences should not be subordinated into this typology exclusively.

1) Feeling slightly rejected.

Some adolescents expressed in the interviews that they felt getting deliberately rejected by their peers. This mostly occurred in public contexts like schools or youth gathering places, and the reason for rejection was identified by the rejected one. Most usually it was appearance, like in the following quote, but social indicators like family background were also named.

'Yeah, so it's like, like I wear boys' clothes, so they might look at you that way, like look what she's wearing. But then, you shouldn't really care, like they've said things to me, and I didn't care at all /.../ so I've come up with this idea, that I know who I am, and even when they say something, I have this idea, and I can't please everyone in this school. So it always hurts a bit, if they don't like you, but they don't really know me, who I am inside." (Female, 15 yrs).

Under this category the adolescents maintained their position as self-sufficient actors despite of feeling rejected by the majority of peers. Getting rejected in a larger peer group did not necessarily mean being all friendless, and they often experienced belonging in close one-on-one friendships or in small and tight group of friends who were "different" together. This kind of position of being an outsider in culturally dominant peer group without being excluded from all practical peer relations was usually described as continuous, but it still did not define the whole self-image of the rejected one. The rejection felt unfair, but "inside" they knew that they are "all right" and accepted by the people who matter to them.

2) Getting victimized.

Not many adolescents in the data reported getting actively bullied or otherwise victimized, neither physically nor verbally, but there were few that explicitly expressed these kinds of experiences. Unlike the "slightly rejected", most of these adolescents identified themselves primarily as the bullied ones and they could only with effort name places or communities of peer belongingness. The experience of being an outsider would be present regardless of the context.

'It's been seven and half years that they've bullied me. Sometimes it's been hard and then you just think that tomorrow will be better, but then it wasn't, so then you think the next day must be a really good day, but it never comes /.../ Like first it was just this one guy, but then they all started, the whole class /.../ When I was little they didn't want to be with me, and when I got older they didn't want to be with me, and they call me names and push me around and blackmail me and won't let me in the room and all that /.../ And I don't know at all why they do this, I try to figure it out every day but I still don't know why, like it's a mystery /.../ No, I don't [have any friends outside of school], I can't remember any since third grade. Like the whole summer, I was all alone at home, skate boarding on my own. Like I wouldn't go on the ramp, I would skate at my home yard alone even though there would be a ramp close by." (Male, 15 yrs).

Unlike the "slightly rejected", the actively victimized adolescents could rarely specify any grounds for their maltreatment. Along with usually constant and long-lasting experience of victimization, the "mystery" of reason brought on the lack of subjectivity and the comprehensive experience of being an outsider, causing the avoidance of peer contact. The descriptions were at a loss and hopeless without expectations of the situation getting any better.

3) Being ignored.

Apart from active rejection experienced by "slightly rejected" and "victimized", there were adolescents in the sample who described themselves as not really getting teased, bullied or rejected, but rather being ignored or neglected in their immediate peer group, like in school or neighborhood. This kind of passive rejection presented itself mainly in not having friends in a larger peer group, although hardly any of the adolescents in this category described close friendships with same-age peers. Instead, several of them portrayed tight kinships or other adult-intensive communities, in which they could feel emotional belonging. 
“I don't really have many friends in my class, well, I don't have any /... I I don't know, it doesn't really have any effect on me /.../ like I don't get bullied or anything /.../ But no, well yeah, sometimes I think of course that it would be nice if there would be someone like me, and if I could finally get friends, but no, I don't really think about it /.../ I'm not lonely /.../ Well, sometimes I talk to my mom's friend." (Female, 15 yrs).

Perhaps because of the family or other significant adult relationships, the ignored adolescents did not feel severely left out. Being outsider in peer group did not extend to all their meaningful communities, leaving space for experiencing inclusion and belonging elsewhere. However, adult relationships do not seem to fully replace the company of peers, as is written in the words in above quote.

Another difference between this category and the previous ones was that being ignored showed as a more temporary position than being actively rejected. These youth often described having friends earlier, for example in childhood or in their previous school. Those friendships had sometimes ended because of a conflict between friends, but more often due to relocation of the family or other incident that did not rest on the adolescent's characteristics or behavior. Thus, their self-esteem was not built on hopeless rejection, but rather on potential of having friends in future as they did before.

4) Outsiders by choice.

The position of adolescents who were situated in the above three categories was dictated by "insiders", that is the dominant mainstream of young people, leaving the "outsider" relatively little room to self-locate or change his/her position as an outsider (this room being more reclaimed by the "ignored" and "slightly rejected", and much less by the "victimized"). Quite the contrary, some adolescents chose to stand outside of the mainstream, describing themselves as not belonging to the peer groups of their everyday living environments in school, neighborhood, other public and semi-public places, or the dominant youth culture. They were outsiders by their own choice.

“Well, I don't really know many young people here who would say in public that they don't drink. It's like when you listen them talk, it's always on Wednesdays, Thursdays, Fridays, like hey, let's get drunk, we're gonna get drunk, and then I'm like no, this is not for me /.../ So yeah, sometimes it feels like they don't want to be with me, but then, I know many people who drink /.../ they think that how can you be a teetotaler, and I then go like, easily, no problem at all." (Female, 15 yrs).

These kinds of "outsider by choice" positions were described as permanent, probably because they were grounded on attitudes and missions that quite naturally are not bared to change in near future. Likewise, these positions were intense and determined. At the same time, however, outsiders by choice reflected their belonging on larger peer group, revealing feelings of being left out. This was largely dependent on whether the adolescent had similar-minded friends with whom he/she could feel belonging together. Quite often being outside the dominant peer culture reinforced the togetherness of the group of outsiders, thus creating belonging through exclusion. Only this time, the excluded ones became "insiders", reflecting the complex connection between belonging and social exclusion.

\subsection{Outsiderness, Emotional Stress, and Loneliness}

Regarding the emotional meaning of experiencing outsiderness, it was studied whether the participants who identified themselves as outsiders expressed emotional stress or depressive feelings. Many indicators of emotional significance of being left out can most clearly be read from the quotes presented in the above section. These feelings of distress expressed by participants are replayed in Table 1.

The figures in Table 1 confirm that although in this sample the victimized adolescents are rare in number, they are the ones experiencing negative emotions most frequently. All victimized adolescents felt sad, hurt and without pleasure, and were avoiding peer contact. All but one of them felt hopelessness and anger, expressed low self-respect, experienced no social support, and told that they are lonely.

As a group or category, the slightly rejected and ignored adolescents expressed experiencing moderate emotional stress. These groups, however, were more heterogeneous than the group of victimized youth, meaning that some rejected or ignored adolescents reported several kinds of stressful symptoms while to others being outsider in peer group seemed to be more or less insignificant. Worth mentioning is that the slightly rejected adolescents, almost all of whom expressed high self-esteem, felt rather confident with future instead of hopelessness or despair, but experienced externalized feelings of anger and hurt relatively more than others. Contradicting, the ignored adolescents' emotions were more self-oriented, as almost half of them felt bored or lonely, lost interest in 
Table 1. Expressed emotional stress by participants who described themselves as outsiders.

\begin{tabular}{|c|c|c|c|c|}
\hline \multirow{2}{*}{ Expressed emotion } & \multicolumn{4}{|c|}{ Expressed by (number of) participants in each category, $n=42$} \\
\hline & rejected, $\mathrm{n}=11$ & victimized, $\mathrm{n}=4$ & ignored, $\mathrm{n}=10$ & by choice, $\mathrm{n}=17$ \\
\hline feelings of sadness & 3 & 4 & 3 & 2 \\
\hline feeling hopeless & 1 & 3 & 1 & 1 \\
\hline feeling hurt/offended & 7 & 4 & 3 & 1 \\
\hline boredom, loss of pleasure & 3 & 4 & 4 & - \\
\hline explicit discontent or anger & 8 & 3 & 3 & 5 \\
\hline low self-esteem/self-respect & 1 & 3 & 3 & - \\
\hline loss of interest with peers & 4 & 2 & 4 & 2 \\
\hline avoid contact with peers & 5 & 4 & 2 & 4 \\
\hline suicidal thoughts & - & 1 & - & - \\
\hline thoughts of revenge & - & 1 & - & - \\
\hline perceived lack of support & 2 & 3 & 4 & - \\
\hline $\begin{array}{l}\text { lack of togetherness or } \\
\text { companionship }\end{array}$ & 6 & 4 & 7 & 2 \\
\hline explicit loneliness & 2 & 3 & 5 & 1 \\
\hline
\end{tabular}

their peers, or felt getting no support from others.

As expected, the outsiders by choice differed notably from other groups. Although largest group in number,they expressed least emotional stress. Nearly one third of them, nevertheless, told about feelings of discontent or anger towards their peers. This was probably because they disagreed in opinion with the mainstream youth. None of the outsiders by choice expressed boredom or loss of pleasure in peer relations, poor self-esteem, or lack of social support, which distinguishes the group from other types of outsiders.

In all groups but outsiders by choice, most of the adolescents expressed that they missed the feeling of togetherness or companionship of other young people. This highlights the meaning of belonging to a meaningful community as a basic need of adolescents. Family relations or adult friends might cut back the need for peer group belonging, but the company of peers cannot be completely replaced by adults.

Loneliness was explicitly expressed by almost all of the victimized and half of the ignored adolescents. Instead, of the slightly rejected youth and of the outsiders by choice close to none told that they would feel lonely. This also demonstrates the importance of experienced belonging that can be received in close friendships in addition to larger peer group: most of the slightly rejected adolescents explained having friends despite of getting rejected in peer group, and several of the outsiders by choice had friends of same opinion, adult friends, or their family relations were tight and satisfactory. Moreover, explicit expressions of loneliness in this sample also indicate that high self-confidence expressed by slightly rejected and voluntarily outsiders prevent or buffer the experience of loneliness-even for rejected adolescents. Also, temporality of outsider experience seemed to go together with rather slight feeling of loneliness, whereas youth who felt constantly left out displayed feeling very lonely.

\section{Discussion}

As voluntary and personally chosen form of social relationships, friendships are important sources of social support, belonging, and self-esteem and, contrarily, of conflict, loneliness, emotional stress, and risk for depression. The main purpose of this study was to investigate adolescents' views about what it means to be excluded in friendship or peer group and how this kind of experience is linked to their emotional wellbeing. The concept of "outsiderness" was used to capture the varying ways of feeling non-belonging in peer group. The study exploited qualitative methodology and the findings were based on adolescents' personal accounts of identifying themselves as "outsiders".

The investigation revealed that one third of the participants, who supposedly represented the average mid- 
dle-class youth in fairly large western (Finnish) cities, experienced "outsiderness" in surrounding peer group. However, these experiences varied greatly, from complete experience of being constantly victimized "by all" to the sense of being rejected in larger peer group while still having close friends, and to the temporary feeling of being ignored in immediate peer group of for example school class. Moreover, most adolescents who identified themselves as outsiders were "outsiders by choice", purposely withdrawing themselves from the dominant youth culture. All of these adolescents, despite of their differing experiences, could be easily misrecognized as lonely from exterior point of view, possibly leading to faulty diagnose. Thus, while the findings are consistent with previous and mostly quantitative studies about peer acceptance, rejection, and popularity (see e.g. Asher \& Coie, 1990; Rubin et al., 1998; Light, 2007), they complement earlier studies with qualitative insight and experiential accounts about adolescents' self-perceived experiences of peer exclusion. These might prove valuable in clinical practice in psychology, psychiatry, social and youth work, in seeking to understand adolescents' lived worlds and their ways of interpreting peer interaction.

Equally important is the finding that "being an outsider", which is often perceived as a far less detrimental attribute than for example "discriminated" or "socially excluded", may mean severe emotional stress and comprehensive experience of loneliness to some adolescents. Studies by Hymel et al. (1990); Dunn (2004); Cotterell (2007); Hopkins (2010), and many others, confirm this notion. Hence, qualitative digging into the individual experience and personal meaning making of self-perceived outsiderness should be overlooked neither in research nor in practice with youth and adolescents.

It could be concluded by the results that it is not "being outsider" in itself that causes problems or emotional strain, but rather it is the feeling of not being part of something: a certain group of same-age peers, a one-on-one friendship, or the youth in general. For some adolescents, not belonging to a group of peers may be a painful experience, as for others, exclusion does not mean loneliness or emotional problems. While it is important to distinguish between problems in popularity and lack of a close friend (see Dunn, 2004), they both need to be recognized as possible causes of distress and depression. Also, the links between personal friendships and peer group status should be examined more carefully to understand their significance for adolescents' wellbeing and adjustment. For example, the present study expressed findings on rejected and ignored adolescents' ability to avoid mental stress partly because their relations with the larger peer group were mediated by their personal friendships. Respectively, the connections between quality of friendship and popularity in larger peer group have been established by Dunn (2004). Accordingly, it would be useful to separate emotional loneliness from social loneliness (e.g. Green et al., 2001; Qualter \& Munn, 2002) and study their presumably distinct relation to adolescent's depression and emotional stress, like the findings of this study on external and more self-oriented feelings ensuing from outsiderness implicated.

The findings of the study are limited in their generalizability, as only a relatively small number of interviews were conducted in a particular context of Finnish teenagers. Social relationships, including those with peers, are formed in time and place, whereupon differences in culture may affect the way that outsiderness, loneliness, or peer relations in general are constructed and perceived. Differences in social, spatial and cultural setting also mean that adolescents have different opportunities to make friends (Dunn, 2004; Korkiamäki \& Kallio, 2014). On the other hand, international comparative studies have demonstrated that the meaning of peer relations, loneliness and its connection with physical, emotional and social risk are not necessarily conditioned by location (Davidson et al., 2008; Stickley et al., 2014). Therefore the findings of this study could presumably be interpreted as relevant in most western cultures and environments. It should also be noticed that the differences between age or gender categories were not particularly addressed in the study, and the ethnic or racial background could have not been taken into account because of the homogeneous research setting. Neither were the reasons behind the experiences of outsiderness studied. Experiences of "insiders" could produce useful information on relationship between reasons of exclusion, loneliness, and emotional stress (see Dunn, 2004). Furthermore, depression and its symptoms are varied and challenged to identify: this study relied only on adolescents' self-reported expressions on their feelings and emotions and on researchers' informed interpretation on what kind of expression could be identified as emotional stress.

Despite these limitations the study represents a fresh perspective on adolescents' varying experiences on social exclusion in peer group. Additionally, three notable grounds are presented for studying young people's friendships and peer relations in the context of depression and emotional disorder in adolescence. Firstly, dealings with friends and peers are among the most focal social encounters in adolescents' lives. If we don't involve and interest ourselves in what goes on between young people and their friends, we are lacking a central part of 
what is important to adolescents from their own point of view. Secondly, adolescents spend a huge amount of time with their peers in school, hobbies, and leisure time activities, in fact they are often in the company of same-age peers more than their families. Much of what is happening in adolescent's everyday lives revolves around peer relations and their consequences. Finally, on one hand, the lack of friendship or satisfactory peer relationship may result in disastrous emotional problems and risk behavior, although this is not necessarily the case. On the other hand, adolescents provide each other with positive feelings, social support, and supportive control, and may also compensate or buffer against the lack of support by adults (Korkiamäki, 2013). This denotes a perspective that could be developed into innovative solutions in dealing with emotional problems and social difficulties in adolescence.

Applying the thinking of Shaw and Gant (2002), if we see adolescents' "being alone" straightforwardly as a problem, we are treating them as a unanimous group and will only see the negative interpretations and unfavorable consequences. What we will miss then, are the variety of experiences, of which some are voluntary and chosen and others entail positive potential in spite of challenging premises. Also, if we only focus on negative side of peer relations, the potential resources and benefits of young people's mutual interaction may be unremarked (cf. Thorsteinsson \& Davey, 2014). Good examples of these resources are the peer support networks and interventions that have often proven to be effective in dealing with emotional problems (e.g. Pfeiffer et al., 2011). Even in most problematic youth communities or disadvantageous relationships there might be positive potential and unutilized resources that could be further mobilized. If the adolescents are given the opportunity and means to disentangle themselves from negative categories of poor peer relations, they might be recognized in new ways by others as well as by themselves. New friendships are often created through family relations, change of school, new hobbies, or virtual networks, and sometimes the seemingly few or none peer ties are nothing to be concerned about. Loneliness in itself is not pathological, and it should be put into the context of young person's own meaning-making, preferences, and personal biography. Acknowledging the variety in experienced loneliness may thus be the key to reinforcing existent and building new communities of belonging.

\section{Acknowledgements}

This study is supported by the Academy of Finland Research Program on the Health and Welfare of Children and Young People (SKIDI-KIDS) (Project 264436). Also, I thank the members of Space and Political Agency Research Group (SPARG) at University of Tampere for inspiring research environment and access to the worthy data. The comments by anonymous reviewers were received with gratitude.

\section{References}

Andersen, S. L., \&Teicher, M. H. (2008). Stress, Sensitive Periods and Maturational Events in Adolescent Depression. Trends in Neurosciences, 31, 183-191.http://dx.doi.org/10.1016/j.tins.2008.01.004

Asher, S. R. \& Coie, J. D. (1990). Peer Rejection in Childhood. New York, NY: Cambridge University Press.

Asher, S. R. \& Paquette, J. A. (2003). Loneliness and Peer Relations in Childhood. Current Directions in Psychological Science, 12, 75-78. http://dx.doi.org/10.1111/1467-8721.01233

Benner, A. (2011). Latino Adolescents' Loneliness, Academic Performance, and the Buffering Nature of Friendships. Journal of Youth \& Adolescence, 40,556-567.http://dx.doi.org/10.1007/s10964-010-9561-2

Brage, D. (1993) Correlates of Loneliness among Midwest Adolescents. Adolescence, 28, 685-694.

Byrne, D. G., Davenport, S. C., \& Mazanov, J. (2007). Profiles of Adolescent Stress: The Development of the Adolescent Stress Questionnaire (ASQ). Journal of Adolescence, 30, 393-416.http://dx.doi.org/10.1016/j.adolescence.2006.04.004

Costello, E. J., Mustillo, S., Erkanli, A., Keeler, G., \& Angold, A. (2003). Prevalence and Development of Psychiatric Disorders in Childhood and Adolescence. Archives of General Psychiatry, 60, 837-844. http://dx.doi.org/10.1001/archpsyc.60.8.837

Cotterell, J. (2007) Social Networks in Youth and Adolescence (2nd ed.). London: Routledge.

Davidson, L. M., Demaray, M. K., Malecki, C. K., Ellonen, N., \& Korkiamäki, R. (2008). United States and Finnish Adolescents’ Perceptions of Social Support: A Cross-Cultural Analysis. School Psychology International, 29, 363-375. http://dx.doi.org/10.1177/0143034308093675

Dumont, M., \& Provost, M. A. (1999). Resilience in Adolescents: Protective Role of Social Support, Coping Strategies, Self-Esteem, and Social Activities on Experience of Stress and Depression. Journal of Youth and Adolescence, 28, 343363. http://dx.doi.org/10.1023/A:1021637011732 
Dunn, J. (2004). Children's Friendships. The Beginnigs of Intimacy. Malden, MA: Blackwell Publishing.

Eddles-Hirsch, K. (2012). Insiders or Outsiders: The Role of Social Context in the Peer Relations of Gifted Students. Roeper Review, 34, 53-62.http://dx.doi.org/10.1080/02783193.2012.627554

Goodwin, M. H. (2006). The Hidden Life of Girls.Games of Stance, Status, and Exclusion. Malden, MA: Blackwell Publishing.http://dx.doi.org/10.1002/9780470773567

Goodyer, I. M., Wright, C. \& Altham, P. M. (1989). Recent Friendships in Anxious and Depressed School Age Children. Psychological Medicine, 19, 165-174.http://dx.doi.org/10.1017/S0033291700011119

Goosby, B., Bellatorre, A., Walsemann, K., \& Cheadle, J. (2013). Adolescent Loneliness and Health in Early Adulthood. Sociological Inquiry, 83, 505-536. http://dx.doi.org/10.1111/soin.12018

Goswick, R. A., \& Jones, W. H. (1982). Components of Loneliness during Adolescence. Journal of Youth and Adolescence, 11, 373-383. http://dx.doi.org/10.1007/BF01540375

Green, L. R., Richardson, D., Lago, T., \& Schatten-Jones, E. C. (2001). Network Correlates of Social and Emotional Loneliness in Young and Older Adults. Personality and Social Psychology Bulletin, 27, 281-288. http://dx.doi.org/10.1177/0146167201273002

Hankin, B. L. (2006). Adolescent Depression: Description, Causes, and Interventions. Epilepsy \& Behavior, 8, 102-114. http://dx.doi.org/10.1016/j.yebeh.2005.10.012

Hopkins, P. (2010). Young People, Place and Identity. London: Routledge.

Hymel, S., Wagner, E., \& Butler, L. J. (1990). Reputational Bias: View from the Peer Group. In S. R. Asher, \& J. D. Coie (Eds.), Peer Rejection in Childhood (pp. 156-186). New York: Cambridge University Press.

Jafari, F., Yousefi, Z., \& Manshaee, G. R. (2014). Mothers Characters and Adolescence Depression. Open Journal of Depression, 3, 45-51. http://dx.doi.org/10.4236/ojd.2014.32010

Junttila, N. (2010). Social Competence and Loneliness during the School Years. Issues in Assessment, Interrelations and Intergeneral Transmission. Ph.D. Thesis, Turku: University of Turku.

Kallio, K. P. (2014). Rethinking Spatial Socialization as a Dynamic and Relational Process of Political Becoming. Global Studies of Childhood, 4, 19.

Korkiamäki, R. (2013). Kaveria ei jätetä! Sosiaalinen pääoma nuorten vertaissuhteissa (No Friend Left Behind! Social Capital and Young People's Peer Realations). Tampere: Tampere University Press \& Finnish Youth Research Society.

Korkiamäki, R., \& Ellonen, N. (2010). Ikätoverisuhteet sosiaalisina resursseina yläkouluiässä (Peer Relations as Social Resource among Teenagers). Nuorisotutkimus (Youth Research), 8, 18-35.

Korkiamäki, R., \& Kallio, K. P. (2014). Ystävyys tilallisen kiinnittymisen suuntaajana: Tilateoreettisia tulkintoja lasten ja nuorten ystävyyksistä (The Role of Friendship in the Formation of Spatial Attachments: Spatial Theoretical Approach to Children’s and Young People’s Friendships). Aluejaympäristö (Space and Environment), 43, 16-33.

Ladd, G., \& Ettekal, I. (2013). Peer-Related Loneliness across Early to Late Adolescence: Normative Trends, Intra-Individual Trajectories, and Links with Depressive Symptoms. Journal of Adolescence, 36, 1269-1282. http://dx.doi.org/10.1016/j.adolescence.2013.05.004

Light, J. M. (2007) Early Adolescent Antisocial Behavior and Peer Rejection: A Dynamic Test of a Developmental Process. New Directions for Child and Adolescent Development, 118, 77-89. http://dx.doi.org/10.1002/cd.202

Mason, J. (2002). Qualitative Researching. London: Sage Publications.

Mayring, P. (2000). Qualitative Content Analysis. Forum Qualitative Sozialforschung/Forum Qualitative Social Research, 1, Article No. 20. http://www.qualitative-research.net/fqs-texte/2-00/2-00mayring-e.htm

Moon, S. S., \& Rao, U. (2010). Youth-Family, Youth-School Relationship, and Depression. Child \& Adolescent Social Work Journal, 27, 115-131. http://dx.doi.org/10.1007/s10560-010-0194-9

Orth, U., Robins, R. W., \& Roberts, B. W. (2008). Low Self-Esteem Prospectively Predicts Depression in Adolescence and Young Adulthood. Journal of Personality and Social Psychology, 95, 695-708. http://dx.doi.org/10.1037/0022-3514.95.3.695

Ortner, S. (2002). Subjects and Capital: A Fragment of a Documentary Ethnography. Journal of Anthropology, 67, 9-32.

Pfeiffer, P. N., Heisler, M., Piette, J. D., Valenstein, M., \& Rogers, M. (2011). Efficacy of Peer Support Interventions for Depression: A Meta-Analysis. General Hospital Psychiatry, 33, 29-36.

http://dx.doi.org/10.1016/j.genhosppsych.2010.10.002

Qualter, P., \& Munn, P. (2002).The Separateness of Social and Emotional Loneliness in Childhood. Journal of Child Psychology and Psychiatry, 43, 233-244. http://dx.doi.org/10.1111/1469-7610.00016

Romeo, R. D. (2010). Adolescence: A Central Event in Shaping Stress Reactivity. Developmental Psychobiology, 52, 244253. 
Rönkä, A. R., Rautio, A., Koiranen, M., Sunnari, V., \& Taanila, A. (2014). Experience of Loneliness among Adolescent Girls and Boys: Northern Finland Birth Cohort 1986 Study. Journal of Youth Studies, 17, 183-203. http://dx.doi.org/10.1080/13676261.2013.805876

Rubin. K. H., Bukowski, W., \& Parker, J. G. (1998). Peer Interactions, Relationships and Groups. In W. Damon, \& N. Eisenberg (Eds.), Handbook of Child Psychology (pp. 619-700). New York: Wiley.

Rueger, S., Malecki, C., \& Demaray, M. (2010). Relationship between Multiple Sources of Perceived Social Support and Psychological and Academic Adjustment in Early Adolescence: Comparisons across Gender. Journal of Youth and Adolescence, 39, 47-61. http://dx.doi.org/10.1007/s10964-008-9368-6

Shavers, C. A. (2014). Commentary: Emotional Problems and Depression among Children and Adolescents in Today's Society. Open Journal of Depression, 3, 74-87. http://dx.doi.org/10.4236/ojd.2014.32012

Shaw, L. H., \& Gant, L. M. (2002). In Defense of the Internet: The Relationship between Internet Communication and Depression, Loneliness, Self-Esteem, and Perceived Social Support. Cyber Psychology \& Behavior, 5, 157-171. http://dx.doi.org/10.1089/109493102753770552

Shugart, M. A., \& Lopez, E. M. (2002). Depression in Children and Adolescents. When “Moodiness” Merits Special Attention. Postgraduate Medicine, 112, 53-56.

Stickley, A., Koyanagi, A., Koposov, R., Schwab-Stone, M., \& Ruchkin, V. (2014). Loneliness and Health Risk Behaviours among Russian and U.S. Adolescents: A Cross-Sectional Study. BMC Public Health, 14, 366. http://dx.doi.org/10.1186/1471-2458-14-366

Thorsteinsson, E. B., \& Davey, L. (2014). Adolescents’ Compulsive Internet Use and Depression: A Longitudinal Study. Open Journal of Depression, 3, 13-17. http://dx.doi.org/10.4236/ojd.2014.31005

Thorsteinsson, E. B., Ryan, S. M., \& Sveinbjornsdottir, S. (2013). The Mediating Effects of Social Support and Coping on the Stress-Depression Relationship in Rural and Urban Adolescents. Open Journal of Depression, 2, 1-6. http://dx.doi.org/10.4236/ojd.2013.21001

Titscher, S., Meyer, M., Wodak, R., \& Vetter, E. (2000). Methods of Text and Discourse Analysis. London: Sage.

Valdez, C., Lambert, S. F., \& Ialongo, N. S. (2011). Identifying Patterns of Early Risk for Mental Health and Academic Problems in Adolescence: A Longitudinal Study of Urban Youth. Child Psychiatry \& Human Development, 42, 521-538. http://dx.doi.org/10.1007/s10578-011-0230-9

Vanhalst, J., Klimstra, T., Luyckx, K., Scholte, R., Engels, R., \& Goossens, L. (2012). The Interplay of Loneliness and Depressive Symptoms across Adolescence: Exploring the Role of Personality Traits. Journal of Youth and Adolescence, 41, 776-787. http://dx.doi.org/10.1007/s10964-011-9726-7

Whitehouse, A., Durkin, K., Jaquet, E., \& Ziatas, K. (2009). Friendship, Loneliness, and Depression in Adolescents with Asperger's Syndrome. Journal of Adolescence, 32, 309-322. http://dx.doi.org/10.1016/j.adolescence.2008.03.004 
Scientific Research Publishing (SCIRP) is one of the largest Open Access journal publishers. It is currently publishing more than 200 open access, online, peer-reviewed journals covering a wide range of academic disciplines. SCIRP serves the worldwide academic communities and contributes to the progress and application of science with its publication.

Other selected journals from SCIRP are listed as below. Submit your manuscript to us via either submit@scirp.org or Online Submission Portal.
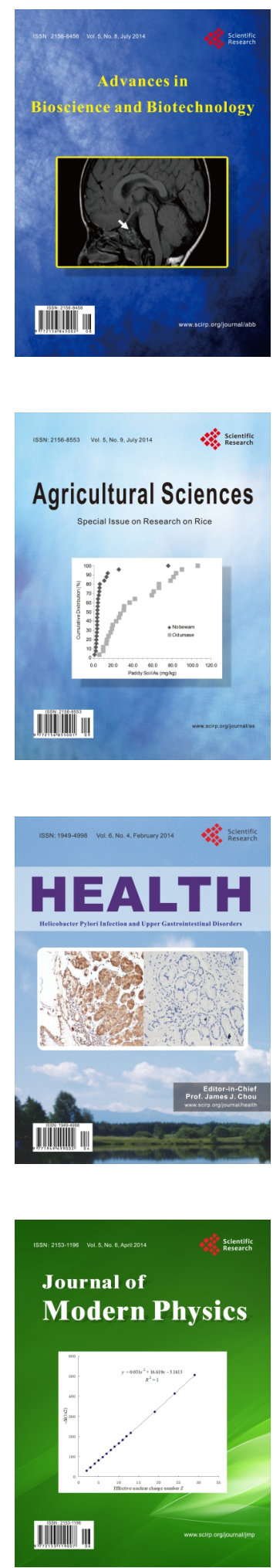
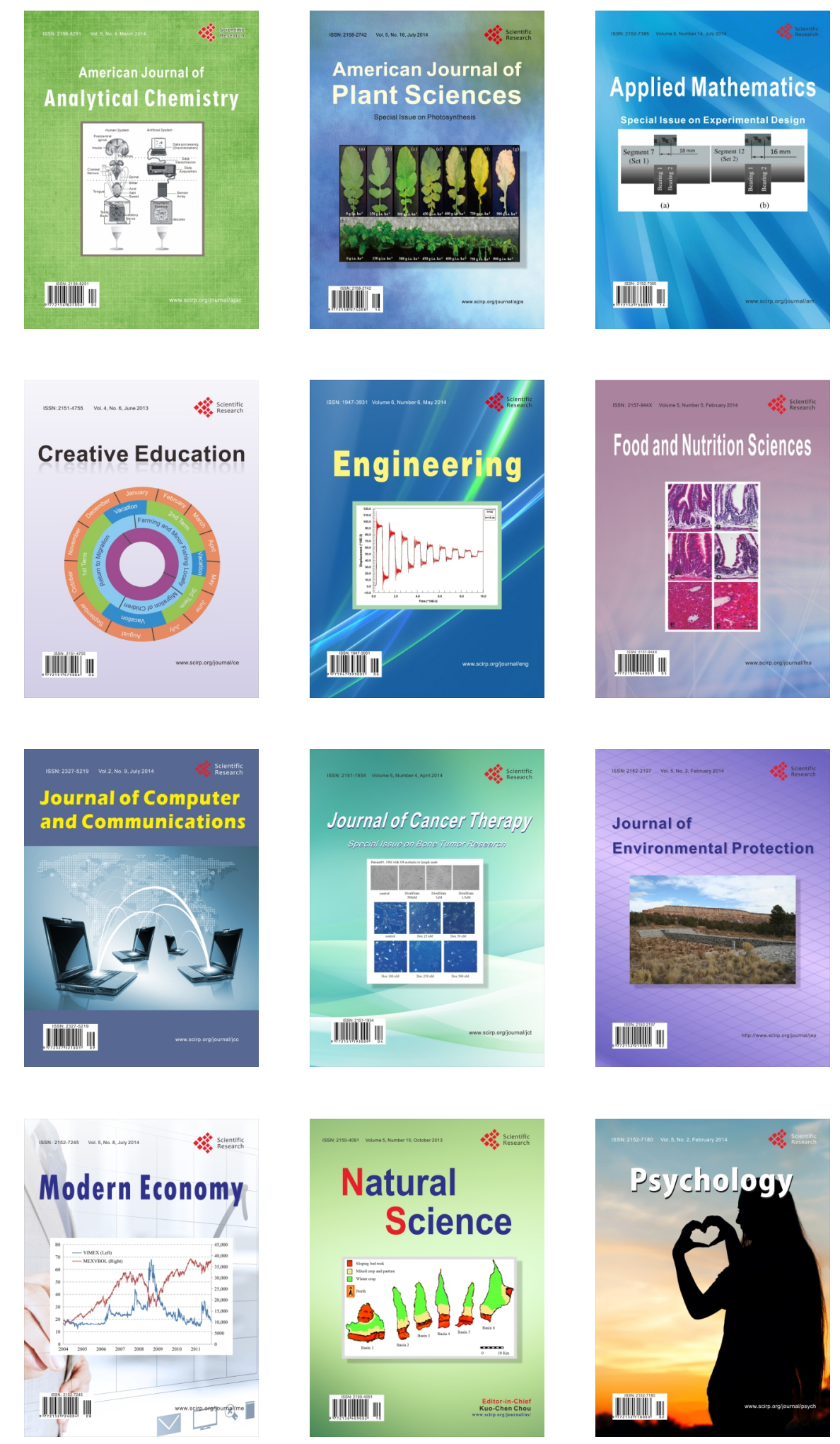